EESTI NSV TEADUSTE AKADEEMIA TOIMETISED, 25. KOIDE KEEMIA * GEOLOOGIA. 1976, Nr. 3

ИЗВЕСТИЯ АКАДЕМИИ НАУК ЭСТОНСКОП ССР. ТОМ 25 ХИМИЯ * ГЕОЛОГИЯ. 1976, № 3

\title{
СОСТАВ ТЯЖЕЛОЙ СЛАНЦЕВОЙ СМОЛЫ. ХАРАКТЕРИСТИКА ПРОДУКТОВ ТЕРМОЛИЗА НЕЙРАЛЬНОЙ ЧАСТИ СМОЛЫ
}

Ранее $\left[{ }^{1,2}\right.$ ] показано, что высококипящая смола полукоксования эстонского горючего сланца-кукерсита содержит в большом количестве соединения, имеющие длинные алкильные цепи. Высказано мнение, что указанная смола является неполностью разложившимся керогеном. Целью настоящей работы было разделение смолы на химические группы и установление различий в структуре отдельных групп с помощью низкотемпературной термической деструкции.

Объектом исследования служил остаток перегонки генераторной смолы, характеристика которой приведена в [']. Кислые соединения выделяли из смолы щелочью, а асфальтены осаждали петролейным эфиром. Обработанную смолу разделяли на группы хроматографированием на силикагеле марки KCM $(0,1-0,25$ мм) при соотношении адсорбента и вещества 10:1. Выход отдельных групп смолы и их характеристики даны в табл. 1. Основными компонентами являются кислородные соединения. Выход кислых соединений - фенолов - также довольно высок.

Таблица 1

Характеристика групп соединений, выделенных из тяжелой сланцевой смолы

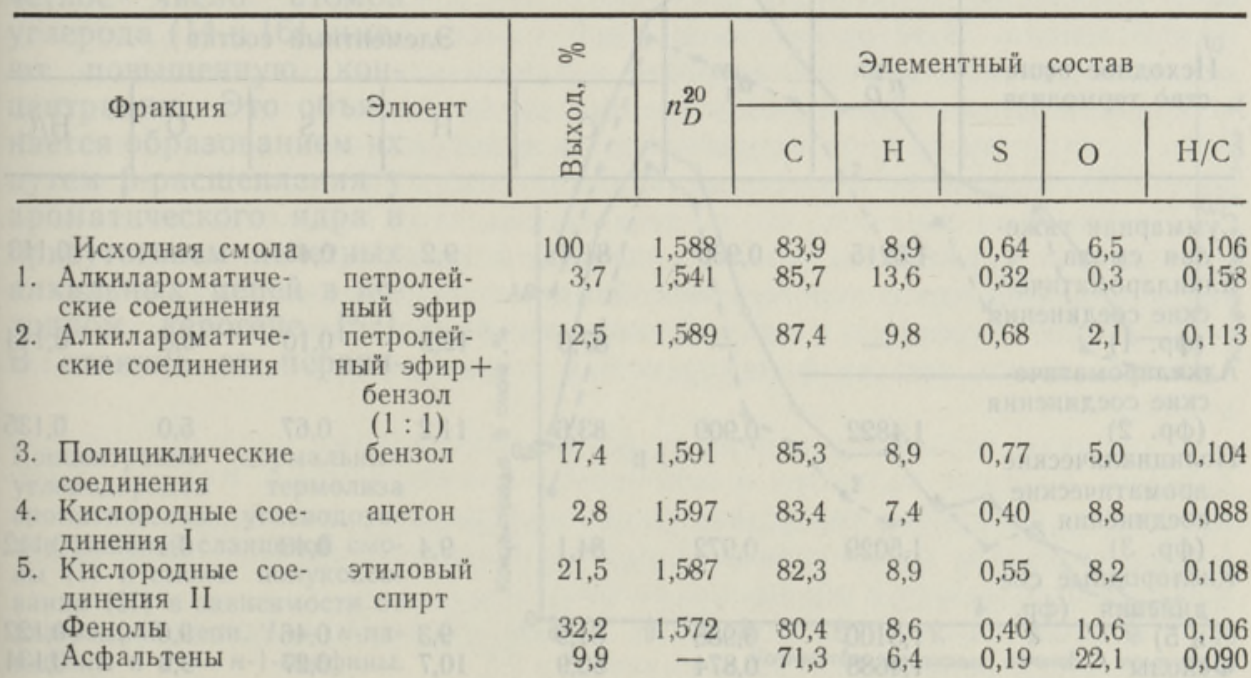


Заметно, что показатели преломления и соотношения $\mathrm{H} / \mathrm{C}$ у отдельных групп довольно близки. Основное различие состоит в содержании кислорода.

Термическое разложение (деструктивная дистилляция) исследуемых групп смолы проводили в колбах для перегонки (ГОСТ 10394-63; объем $100 \mathrm{M} \Omega)$, нагреваемых в тигельной печи. Летучие продукты деструкции собирали в приемник, охлаждаемый льдом. Количество и состав газа не определяли. Температуру колбы (измеряемую в жидкой фазе) быстро поднимали до $300^{\circ} \mathrm{C}$, а затем со скоростью $1,5^{\circ}$ в минуту - до $450^{\circ}$. Выход продуктов деструкции приведен в табл. 2.

В данных условиях опыта часть высококипящих продуктов термолиза не перегонялась. Для выделения их кокс экстрагировали бензолом. По данным элементного анализа в экстрактах присутствуют полициклические ароматические соединения, содержащие также кислород [3]. Так

таблица 2

Выход продуктов при термолизе тяжелой смолы и ее групп

\begin{tabular}{|c|c|c|c|c|c|}
\hline \multirow{2}{*}{$\begin{array}{c}\text { Исходное вещество } \\
\text { термолиза }\end{array}$} & \multicolumn{5}{|c|}{ Выход, \% } \\
\hline & $\begin{array}{c}\text { нераст- } \\
\text { воримо- } \\
\text { го кокса }\end{array}$ & $\begin{array}{l}\text { экстрак- } \\
\text { та кокса }\end{array}$ & $\begin{array}{l}\text { дистил- } \\
\text { лята }\end{array}$ & воды & $\begin{array}{l}\text { газа и } \\
\text { потерь }\end{array}$ \\
\hline Суммарная тяжелая смола & 30,0 & 1,7 & 55,7 & 1,7 & 10,9 \\
\hline $\begin{array}{l}\text { Алкилароматические соеди- } \\
\text { нения (фр. 1) }\end{array}$ & 25,2 & - & 52,8 & 3,5 & 18,5 \\
\hline $\begin{array}{l}\text { Алкилароматические соеди- } \\
\text { нения (фр. 2) }\end{array}$ & 36,5 & 5,5 & 48,8 & следы & 9,5 \\
\hline $\begin{array}{l}\text { Полициклические аромати- } \\
\text { ческие соединения (фр.3) }\end{array}$ & 30,8 & 3,7 & 53,6 & следы & 11,5 \\
\hline $\begin{array}{l}\text { Кислородные соединения } \\
\quad \text { (фр. } 4 \text { и 5) } \\
\text { Фенолы } \\
\text { Асфальтены }\end{array}$ & $\begin{array}{l}32,4 \\
36,8 \\
49,5\end{array}$ & $\begin{array}{l}0,8 \\
5,0 \\
3,0\end{array}$ & $\begin{array}{l}53,6 \\
33,4 \\
26,3\end{array}$ & $\begin{array}{l}4,1 \\
5,7 \\
6,8\end{array}$ & $\begin{array}{r}9,1 \\
19,1 \\
14,4\end{array}$ \\
\hline
\end{tabular}

Таблица 3

Характеристика дистиллятов термолиза групп смолы

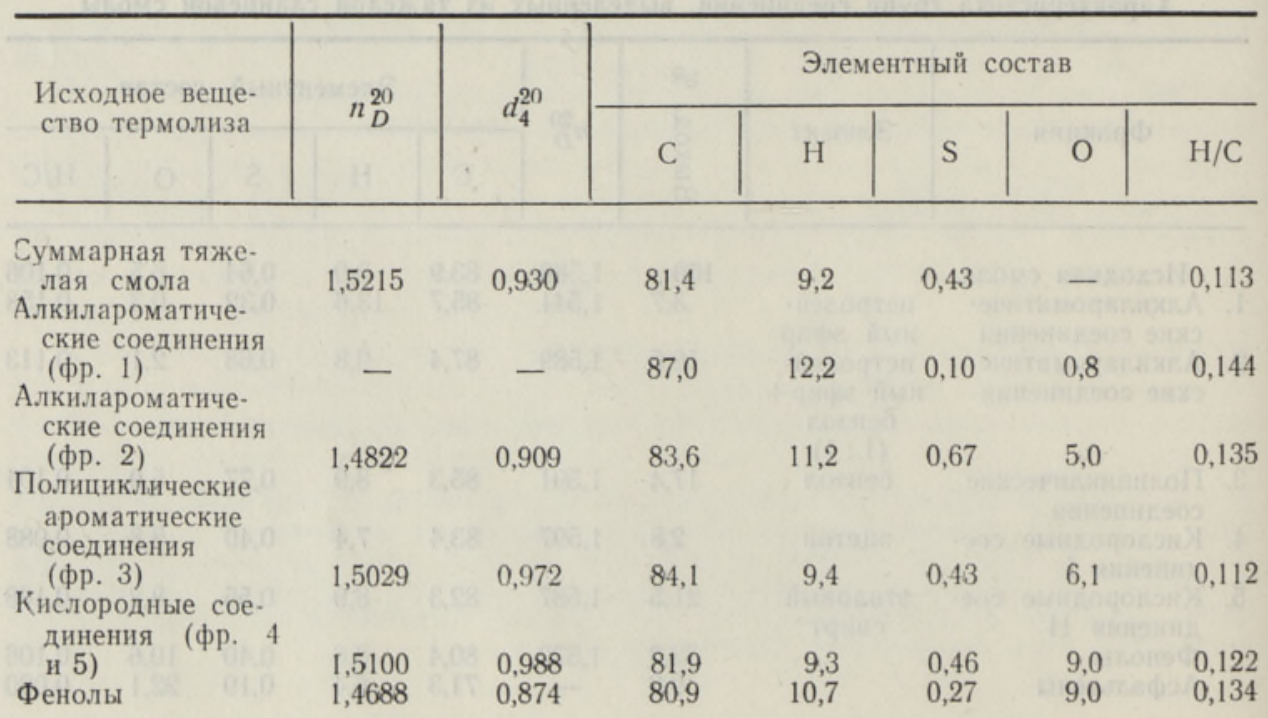


Групповой состав дистиллятов термолиза (вес. \%)

\begin{tabular}{|c|c|c|c|c|c|c|}
\hline $\begin{array}{c}\text { Исходное вещество } \\
\text { термолиза }\end{array}$ & 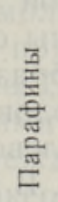 & 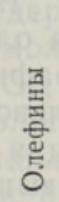 & 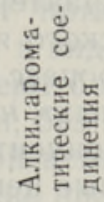 & 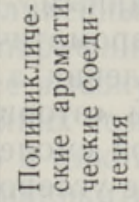 & 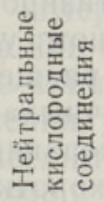 & 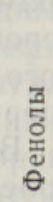 \\
\hline Суммарная тяжелая смола & 9 & 7 & \multicolumn{2}{|c|}{23} & 27 & 34 \\
\hline $\begin{array}{l}\text { Алкилароматические соеди- } \\
\text { нения (фр. } 1)\end{array}$ & 22 & 17 & 9 & 46 & 6 & - \\
\hline $\begin{array}{l}\text { нения (фр. 2) } \\
\text { Полициклические аромати- }\end{array}$ & 16 & 13 & 31 & 25 & 11 & 4 \\
\hline $\begin{array}{l}\text { ческие соединения (фр. } 3 \text { ) } \\
\text { Кислородные соединения }\end{array}$ & $\begin{array}{l}6 \\
8\end{array}$ & $\begin{array}{l}4 \\
7\end{array}$ & $\begin{array}{l}13 \\
21\end{array}$ & $\begin{array}{l}37 \\
13\end{array}$ & $\begin{array}{l}24 \\
22\end{array}$ & $\begin{array}{l}16 \\
29\end{array}$ \\
\hline
\end{tabular}
(фр. 4 и 5 )

как термолиз проводили при относительно низкой температуре, то выход дистиллятов был несколько меньше, чем в предыдущих работах $\left[{ }^{1,2}\right]$. Характеристика жидких продуктов термолиза дана в табл. 3. Летучие продукты термолиза обогащались водородом, причем, как и в исходных фракциях, соотношения $\mathrm{H} / \mathrm{C}$ у них близки.

Обесфеноленные дистилляты разделяли на группы методом препаративной тонкослойной хроматографии $\left[{ }^{4,5}\right]$. Как видно из табл. 4 , из всех групп смолы образуется довольно много парафинов и олефинов, а часть нейтральных кислородных соединений превращается при термолизе в фенолы. Индивидуальный состав выделенных групп определяли газохроматографически на «Хром-4», используя параллельные колонки и пламенно-ионизационный детектор.

Главными компонентами на хроматограммах суммарных дистиллятов были $H$-парафины и соответствующие 1-олефины. Хроматограммы всех дистиллятов схожи и указывают (в отличие от данных табл. 4) на почти равное содержание алифатических углеводородов в них.

Как и в первичных смолах полукоксования, олефины, содержащис четное число атомов углерода (14 и 16), имеют повышенную концентрацию. Это объясняется образованием их путем $\beta$-расщепления у ароматического ядра и присутствием нечетных алкильных цепей в исходном керогене $[6,7]$. В отличне от первич-

Концентрация нормальных углеводородов термолиза ароматических углеводородов тяжелой сланцевой смолы (I) и смолы полукоксования (II) в зависимости от углеродной цепи. $1-\boldsymbol{H}$-парафины и $2-\mu$-1-олефины.

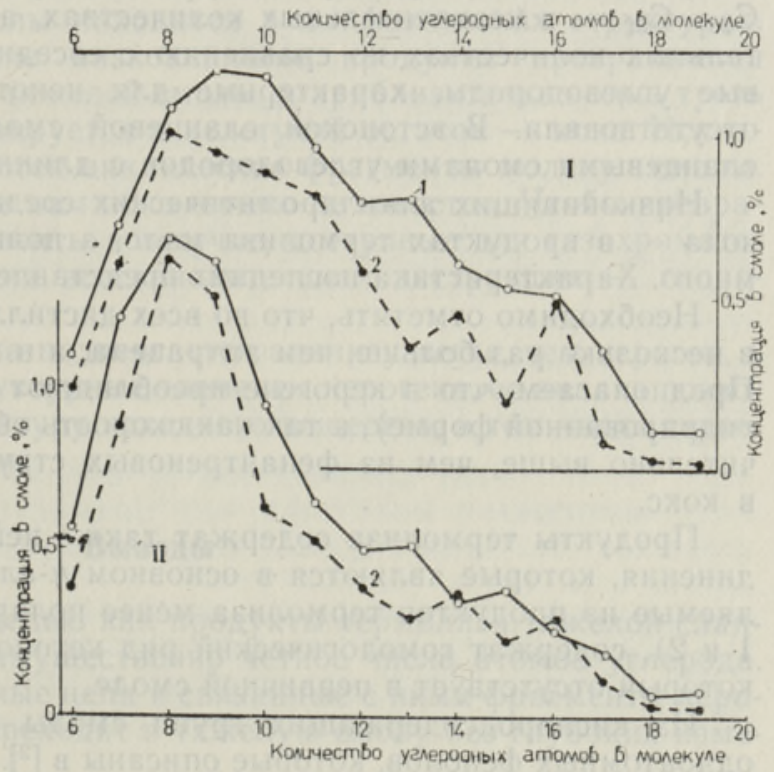


ной смолы в данном случае концентрация парафинов изменяется монотонно с удлинением углеродной цепи. Это обусловлено более ароматизированным характером тяжелой смолы по сравнению с керогеном: у ароматического ядра олефины образуются путем селективного $\beta$-расщепления, а процесс парафинообразования сложнее $\left.{ }^{8}\right]$. Составы «первичных» и «вторичных» н-углеводородов представлены на рисунке.

В первичной смоле концентрация $H$-углеводородов $\mathrm{C}_{8}-\mathrm{C}_{10}$, имеющих более короткие углеродные цепи, выше [9]. В тяжелой смоле цепи разной длины присутствуют в близких концентрациях.

Так как при термической деструкции цепи $\mathrm{C}_{8}-\mathrm{C}_{10}$ отщепляются труднее, чем длинные, логично ожидать, что они остаются связанными в тяжелой смоле. Такое несоответствие можно объяснить тем, что короткие цепи являются составной частью макроциклов керогена, легко разлагаемых при нагреве.

Олефины, полученные в результате термолиза тяжелой смолы, характеризуются высоким содержанием 1-изомеров. Изомерный состав олефинов в пределах $\mathrm{C}_{11}-\mathrm{C}_{17}$ следующий (в скобках приведены соответствующие данные для первичных олефинов) : 1-олефины составляют 60 (43) \%, 2-транс- - 11(14) \%, 2-циис- 8(9) \% и остальные - 21(34\%). Первичные олефины содержат больше изомеров, имеющих двойную связь в середине цепи. Предполагаем, что исходным биологическим материалом этих олефинов были моноеновые жирные кислоты, имеющие двойную связь в середине цепи. При их полимеризации в ходе диагенеза образуются вторичные алкильные цепи [7], которые при термолизе легко отщепляются н поэтому накопляются в продуктах первой термической обработки. Двойная связь при этом восстанавливается на исходном месте - в середине цепи.

В смолах полукоксования некоторых горючих сланцев присутствуют парафины, содержащие до 30 атомов углерода [ $\left.{ }^{10}\right]$. Для определения парафинов фракцию 1 разделяли дополнительно на тонком слое и выделяли фракцию алифатических углеводородов $\left(n_{D}^{20}=1,4735,0,5 \%\right.$ в пересчете на исходную смолу). С помощью газохроматографической колонки, употребляемой для высокотемпературного анализа, установили, что в тяжелой смоле присутствуют нормальные углеводороды $\mathrm{C}_{14}-\mathrm{C}_{32}$, причем $\mathrm{C}_{26}-\mathrm{C}_{32}$ - в незначительных количествах, а $\mathrm{C}_{23}$ и $\mathrm{C}_{25}-$ в более значительных количествах по сравнению с соседними гомологами. Изопреновые углеводороды, характерные для некоторых ископаемых осадков, отсутствовали. В эстонской сланцевой смоле по сравнению с другими сланцевыми смолами углеводородов с длинными цепями очень мало.

Низкокипящих алкилароматических соединений - производных бензола - в продуктах термолиза мало, а полициклических соединений много. Характеристика последних представлена в ['].

Необходимо отметить, что во всех дистиллятах термолиза фенантрена в несколько раз больше, чем антрацена, а в первичных смолах наоборот. Предполагаем, что в керогене преобладают антраценовые структуры (в гидрированной форме), а так как скорость образования кокса из них значительно выше, чем из фенантреновых структур $\left[{ }^{11}\right]$, они превращаются в кокс.

Продукты термолиза содержат также нейтральные кислородные соединения, которые являются в основном н-алкилкетонами. Кетоны, выделяемые из продуктов термолиза менее полярных групп смолы (фракции 1 и 2), содержат гомологический ряд кетонов с неизвестной структурой, который отсутствует в первичной смоле.

Из кислородсодержащих групп смолы образуется довольно много одноатомных фенолов, которые описаны в $\left[{ }^{2}\right]$. 


\section{Обсуждение результатов}

Все группы тяжелой смолы содержат прямолинейные углеродные цепи, которые отщепляются при термолизе в виде парафинов или олефинов. Тот факт, что 1-олефины $\mathrm{C}_{14}$ и $\mathrm{C}_{16}$ имеют более высокую коншентрацию по сравнению с соседними гомологами, без всяких сомнений, указывает на сохранение связи между алкильной цепью и циклическим фрагментом керогена при полукоксовании. Можно предположить, что и другие циклические структурные элементы отражают строение исходного вещества, т. е. тяжелая сланцевая смола полукоксования является осколком нсходного керогена.

Об образовании высококипящих смол при низкотемпературной деструкции твердого топлива существуют разные предположения. Предполагается, например, что в конденсационных системах сланцеперегонных установок низкомолекулярные продукты смолы полимеризуются, в результате чего образуется часть тяжелой смолы $\left[{ }^{12}\right]$. Существует также мнение, что парафины с длинной цепью, присутствующие в продуктах полукоксования каменного угля, являются продуктами полимеризации низкомолекулярных олефинов $\left[{ }^{13,14}\right]$. Однако образование прямолинейных углеродных цепей в условиях полукоксования невозможно с точки зрения термодинамики. Результаты настоящей работы показывают ошибочность перечисленных предположений.

Углеводороды термолиза отдельных групп тяжелой сланцевой смолы по своему индивидуальному составу мало различаются. Различие установлено главным образом по содержанию кислорода и полициклических структур.

Еще недавно $\left[{ }^{15}\right]$ тяжелую смолу рассматривали как смесь ароматических кислородных соединений. Результаты настоящей работы показывают, что не менее $30 \%$ углерода нейтральной смолы находится в прямолинейных углеродных цепях, при этом учтены только алифатические составляющие продуктов термолиза. Количество алифатического углерода, несомненно, еще больше, так как при термолизе происходят также ароматизация и глубокое изменение алифатических структур. Лилле и др. $\left[{ }^{16-18}\right]$ на основе данных ЯМР-спектроскопии предполагают даже, что $60 \%$ углерода тяжелой смолы находится в алифатических структурах.

При термолизе в жидкие низкокипящие продукты превращается немногим больше половины тяжелой смолы, а приблизительно одна треть конденсируется и полимеризируется в нелетучий остаток - кокс. Исходным веществом кокса являются циклические фрагменты молекул смолы. О строении этих фрагментов нам пока ничего не известно. Чтобы превратить полициклические фрагменты в летучие, доступные для газохроматографического анализа, нужна восстановительная деструкция - гидрокрекинг.

Тяжелая сланцевая смола подвергается анализу легче, чем кероген, á так как смола содержит структурные элементы керогена, ее анализ позволяет установить также структуру исходного вещества, в том числе строе ние циклических фрагментов.

\section{Выводы}

1. Олефины с длинной цепью как продукты термолиза тяжелой сланцевой смолы содержат преимущественно четное число атомов углерода. Это показывает, что алкильные цепи и связанные с ними фрагменты керогена при полукоксовании переходят в тяжелую смолу без глубоких изменений. 
2. Группы соединений нейтральной тяжелой смолы содержат тождественные углеводородные структуры. Они различаются главным образом по содержанию кислорода и полициклических структур.

\section{Л И Т Е РА Т У Р А}

1. Клесмент И., Риккен Ю., Эйз ен О., Пур ре Т., Изв. АН ЭССР, Хим. Геол., 21, № 1, 3 (1972).

2. Риккен Ю., Салусте С., Клесмент И., Пурре Т., Эйзен О., Изв. АН ЭССР, Хим. Геол., 22, № 2, 131 (1972).

3. Л а хе Л., Э й з е н О., Изв. АН ЭССР, Хим. Геол., 18, № 3, 225 (1969).

4. К а сб ерг А. Ф., Кл ес м н т И. Р., Химия твердого топлива, № 1, 107 (1969).

5. Kle sm e n t I., J. Chromatog., 91, 705 (1974).

6. Клес ме н т И. Р., Химия твердого топлива, № 2, 33 (1973).

7. Кл есм ен т И. Р., Химия твердого топлива, № 3, 112 (1973).

8. W i e l A., Erdöl-Erdgas-Zeitschr., 85, № 2, 51 (1969).

9. Клесм ент И., У ров К., Эй зен О., Изв. АН ЭССР, Хим. Геол., 22, № 4, 306 (1973).

10. К лес м ен т И. Р., С ал у с т е С. Я., Э й з ен О. Г., Химия твердого топлива, № 4, 137 (1971)

11. М агарил Р. 3., Образование углерода при термических превращениях индивидуальных углеводородов и нефтепродуктов, М., 1973.

12. С еменов С. С., З аб родин В. И., Химия и технология топлива и продуктов его переработки, вып. 8, Л., 1959 , с. 75.

13. Maher T. P., J. Chromatog., 10, 324 (1963).

14. $M$ a her T. P., Fuel, 47, № 5, 359 (1968).

15. Әй зен О. Г., Методы анализа смол переработки твердого топлива и химический состав эстонской сланцевой смолы. Автореф. докт. дис., Таллин, 1967.

16. Л илле Ю., Пехк Т., Пурре Т., Биттер Л., Изв. АН ЭССР, Хим. Геол., 22, № 1,17 (1973).

17. Л илле Ю. Э., Пурре Т. А., Дойлов С. К., Пехк Т. И., Мурд А. Г., Кай д аш Н. Ю., Высоцкая В. В., Тр. Таллинск. политехн, ин-та, серия А, № 332, 185 (1973).

18. Лилле Ю. Э., Исследования в области алкилрезорцинов. Автореф. докт. дис., Таллин, 1973.

Институт химии
Академии наук Эстонской ССР

Поступила в редакцию $29 /$ III 1974

\section{KLESMENT, Juta RIKKEN, O. EISEN}

\section{RASKE POLLEVKIVIÓLI KOOSTIS. NEUTRAALOLI TERMOLOUSIPRODUKTIDE ISELOOMUSTUS}

Õist adsorptsioonkromatograafiliselt eraldatud grupid lagundati temperatuuril $300-$ $450{ }^{\circ} \mathrm{C}$ ja uuriti saadud vedelproduktide koostist. Paarisarvu süsinikaatomitega 1-olefiinidel on kõrge kontsentratsioon. Järeldatakse, et raskeōli aromaatsete struktuuridega seotud pikad ahelad sisaldavad peamiselt 13,15 ja 17 süsinikuaatomit. Raskeôli on pooleldi lagunenud kerogeen.

\section{KLESMENT, Juta RIKKEN, O. EISEN}

\section{THE COMPOSITION OF ESTONIAN OIL SHALE SEMICOKING HEAVY TAR. THE CHARACTERIZATION OF NEUTRAL TAR THERMAL DECOMPOSITION PRODUCTS}

Compound groups separated from tar by adsorption chromatography were submitted to cracking at $300-450^{\circ} \mathrm{C}$ and the composition of liquid products was investigated. Even carbon numbered 1-olefins are present in elevated concentrations inferring to long hydrocarbon chains that contain mostly 13,15 and 17 carbon atoms and are attached to aromatic structures of heavy tar. Heavy tar is an intermediate of kerogen thermal fission. 